\title{
Effect of Wnt signaling pathway on pathogenesis and intervention of neuropathic pain
}

\author{
YU ZHAO and ZHANYUN YANG \\ Department of Anesthesiology, Jining No. 1 People's Hospital, Jining, Shandong 272011, P.R. China
}

Received May 7, 2018; Accepted July 20, 2018

DOI: $10.3892 /$ etm.2018.6512

\begin{abstract}
Neuropathic pain (NP) is a common clinical chronic pain with very complex mechanisms. This study explored the function of activated Wnt signaling pathway in NP. A rat model of chronic constriction injury (CCI) was established. Different doses of IWP-2, a Wnt signal inhibitor, were intrathecally injected to observe the behavior indicators at different time-points, including the pain induced by mechanical stimulation and thermal stimulation. The mRNA and protein levels of Wnt-3a, Frizzled 4 and $\beta$-catenin in lumbar (L) 4-6 dorsal root ganglion (DRG) of rats in each group, as well as synaptic plasticity-related molecules in DRG region of rats were detected by RT-PCR and western blotting, respectively. Compared with Sham group and Naive group, paw withdrawal thermal latency and paw withdrawal mechanical threshold were significantly decreased after CCI, while synaptic plasticity was increased $(\mathrm{P}<0.05)$. Besides, activation of $\mathrm{Wnt} / \beta$-catenin signaling pathway was observed in rats with CCI. We found that intrathecal injection of IWP-2 effectively relieved the pain behavior and reduced the synaptic plasticity in rats with neuropathic pain after CCI, suggesting that the inactivated $\mathrm{Wnt} / \beta$-catenin signaling pathway might be the major mechanism responsible for this effect. Our data demonstrated that intrathecal injection of IWP-2 ameliorated neuropathic pain in CCI rats by inhibiting the $\mathrm{Wnt} / \beta$-catenin pathway.
\end{abstract}

\section{Introduction}

Neuropathic pain (NP) is caused by primary injury or dysfunction of the nervous system with very complex pathogenesis. However, no effective cure has been developed so far $(1,2)$. NP is currently considered as one of the pain syndromes that is most difficult to cure. Millions of patients worldwide are

Correspondence to: Dr Zhanyun Yang, Department of Anesthesiology, Jining No. 1 People's Hospital, 6 Jiankang Road, Rencheng, Jining, Shandong 272011, P.R. China

E-mail: inzic281@163.com

Key words: neuropathic pain, IWP-2, CCI, Wnt/ $\beta$-catenin signaling pathway plagued by NP, which brings great trouble to their daily activities (3-5). It has now been clarified that NP is closely related to the accumulation of ion channels in impaired sites, sympathetic sprouting, $A \beta$ fiber sprouting, central sensitization and depressive effects (6-9). In addition, long-term NP is reported to be associated with altered genes. With further study of glial cells, SP, vasoactive intestinal peptide, purinergic receptor and CGRP, the pathogenesis of NP has been explored in recent years $(10,11)$. NP is a common clinical disease, but there are still many problems such as poor efficacy, poor tolerance and adverse reactions $(4,12)$.

Peripheral nerve injury induces NP through a series of complex molecular cascade reactions in the dorsal root ganglia and spinal cord, including tumor necrosis factor (TNF- $\alpha$ ), interleukin-6 (IL-6) and nuclear factor- $\kappa \mathrm{B}(\mathrm{NF}-\kappa \mathrm{B})(13,14)$. The intracellular second messenger cyclic adenosine monophosphate (cAMP)-dependent protein kinase A (PKA) and cyclic guanosine monophosphate (cGMP)-dependent protein kinase $\mathrm{G}(\mathrm{PKG})$ mediate hyperalgesia and high excitability of compressed neurons in CCD rats (15). In addition, a variety of ion channels are also involved in the delivery of noxious stimuli of dorsal root ganglion (DRG) neurons following sustained compression, such as voltagegated $\mathrm{Na}^{+}$and $\mathrm{K}^{+}$channels, hyperpolarization-activated cation channels, and transient receptor potential vanilloid 4 (TRPV4) (16-18). Recent studies have identified several new signaling pathways associated with neuropathic pain, such as mitogen-activated protein kinase family pathway (MAPK), cytokine and neurotrophic growth factor family pathways, TGF- $\beta$ signaling pathway and 5 -HT2A receptor signaling pathway (19-24).

Wnt signaling pathway is greatly involved in embryonic development and tissue homeostasis, and aberrant Wnt signaling is often related to many serious diseases, including cancer, osteoporosis and other degenerative diseases (25). It is reported that Wnt signaling pathway plays a variety of roles in the development of the nervous system, and activation of downstream signaling is associated with synapse formation, structural and functional regulation (26). Wnt-3a is shown to increase the number of presynaptic synapses in the hippocampal neurons, induce the aggregation of Bassoon component in active region and the release of synaptic vesicles, and increase frequency of excitatory synaptic currents $(27,28)$. The activation of multiple Wnt signals can regulate the plasticity of synapses. 
Because of the extremely complicated factors involved in the formation and maintenance of NP, it is important to identify the exact mechanism of NP and seek safe and effective treatment drugs.

\section{Materials and methods}

Animal. A total of 72 male Sprague-Dawley (SD) rats weighing 180-200 $\mathrm{g}$ at specific pathogen-free (SPF) level were assigned into the control group (Naïve group, $N=12$ ), sham group (Sham group, $\mathrm{N}=30$ ) and treatment group $(\mathrm{N}=30)$. The rats were housed in a temperature controlled room $\left(21 \pm 2^{\circ} \mathrm{C}\right)$ on a 12-h light/dark cycle (lights on at 06:00). All rats had free access to water and food. For the sham group, only the bilateral sciatic nerve was exposed without ligation, while SD rats in the treatment group were subjected to sciatic nerve compression injury to establish the rat chronic constriction injury (CCI) model. This study was approved by the Animal Ethics Committee of Jining No. 1 People's Hospital Animal Center (Jining, China).

Animal behavior assessment. i) Determination of mechanical stimulation-induced pain. All rats were placed in specially customized cages with barbed wire at the bottom. Electronic von Frey measurement was performed to record the minimum stimulus intensity of raising foot reflex in rats, and the measurement interval was 3-4 min. The average value of 3 parallel measurements was recorded as the paw withdrawal mechanical threshold (PWMT).

ii) Determination of heat stimulation-induced pain. The BME-410A thermal radiation pain stimulator was used to irradiate the left and right foot of rats. The irradiation was stopped when rats developed rapid contraction of foot, foot lifting or licking foot reaction. The duration of irradiation was taken as the paw withdrawal thermal latency (PWTL), with an interval over $5 \mathrm{~min}$ for each measurement. The average value of 3 parallel measurements was taken as the PWTL.

iii) Determination of cold stimulation-induced pain. The number of positive appearance of each rat after acetone stimulation was recorded as the total number of withdrawal according to the method proposed by Datta et al (29).

Intrathecal catheter and administration. The rats were anesthetized by intraperitoneal injection of sodium pentobarbital at a dose of $40-50 \mathrm{mg} / \mathrm{kg}$. According to the intersection of the midline and the spine of the rat, a longitudinal incision $\sim 1 \mathrm{~cm}$ was made in the L3-4 space. Then the skin and fascia were cut in sequence, and the muscle tissue was stripped to expose the spinous processes at L5-6. Muscle separation was performed to expose the spinous process at L5-6. Separation of the spinous process on both sides of the muscle and the spine between the initial zones was performed. The yellow zone was then exposed after the muscle and initial zone separated from spinous process. A $22 \mathrm{G}$ needle was punctured through the yellow belt and stopped when the rat flicked. Then, a $2 \mathrm{~cm}$ PE-10 catheter was gently placed into the inferior cranial subarachnoid space and secured when rats flicked or the cerebrospinal fluid slowly outflowed. Rats in the treatment group were intrathecally injected with $10 \mu 1$ of IWP-2 $(20 \mu \mathrm{g} / 20 \mu \mathrm{l})$ for 7 days after CCI. Rats in the naive group received intrathecal administration of saline for 7 days continuously.

Animal specimens collection. Rats were anesthetized by intraperitoneal injection of $0.4 \mathrm{~g} / \mathrm{kg}$ of $10 \%$ chloral hydrate and then sacrificed by decapitation. Under aseptic procedures, the skin and muscle were dissected along the spinous process quickly, and the spinal spinous process was removed using scissors. The L4-6 DRG was immediately stored in $-80^{\circ} \mathrm{C}$ after peeled off from the spinal cord. DRG tissues were collected from rats on the 1st, 3rd, 7th, 14th and 21st day after operation in sham and naive groups. For rats in treatment group, DRG tissues were harvested on the 14th day after operation.

$R T-P C R$. Total RNA was extracted from spinal cord by TRIzol lysate and RNA extraction kit (Invitrogen; Thermo Fisher Scientific, Inc., Waltham, MA, USA). After reverse transcription into complementary Deoxyribose Nucleic Acid (cDNA), polymerase chain reaction was used to amplify the target gene to detect mRNA expression of each target gene in the spinal cord. The primers were designed by Primer Premier 5.0 (Premier Tech Co, Ltd., Quebec, Canada). Wnt-3a, forward, TGGAAACCCAAGCGTCGGAC and reverse, CTACCTGCG GAACGGATCCG; Frizzled 4, forward, ACTGGTAGATGCC GATGAGC and reverse, GCCGCAATGAATAAAGTTCC; $\beta$-catenin, forward. GGCTATACGGACGGGATCGGA and reverse, CCGATTACGTCTGGCTAGGCT; GAPDH, forward, CCCATCTATGAGGGTTACGC and reverse, TTTAATGTCA CGCACGATTTC.

Western blotting. The radioimmunoprecipitation assay (RIPA) method (Beyotime Institute of Biotechnology, Shanghai, China) was used to lyse spinal cord tissue, followed by extraction of total proteins. Protein samples were then separated by conventional electrophoresis and incubated with rabbit polyclonal Wnt-3a antibody (dilution, 1:500; cat. no. ab28472), rabbit polyclonal Frizzled 4 antibody (dilution, 1:500; cat no. ab83042) and rabbit monoclonal $\beta$-catenin antibody (dilution, 1:500; cat. no. ab32572) overnight at $4^{\circ} \mathrm{C}$. After being washed with phosphate-buffered saline (PBS), the membranes were incubated with secondary goat anti-rabbit (HRP) IgG antibody (dilution, 1:2,000; cat. no. ab6721) for $2 \mathrm{~h}$ at room temperature. All the antibodies were purchased from Abcam (Cambridge, MA, USA). Enhanced chemiluminescence imaging (ECL; Beyotime Institute of Biotechnology) was performed, and the integral optical density (IOD) value of each band was determined by $\mathrm{Gel}$ imaging analysis system. $\beta$-actin was taken as the internal reference.

Statistical analysis. Statistical product and service solutions (SPSS) 22.0 software (IBM Corp., Armonk, NY, USA) was used for data analysis. GraphPad Prism 5.0 (Version X; GraphPad Software, Inc., La Jolla, CA, USA) was introduced to edit images. Survival analysis was performed using Kaplan-Meier survival curves. Independent-sample t-test was performed to analyze the difference between the two groups and Chi-square test was performed to analyze the classification data. All data were presented as mean \pm standard deviation. $\mathrm{P}<0.05$ was considered to indicate a statistically significant difference. 

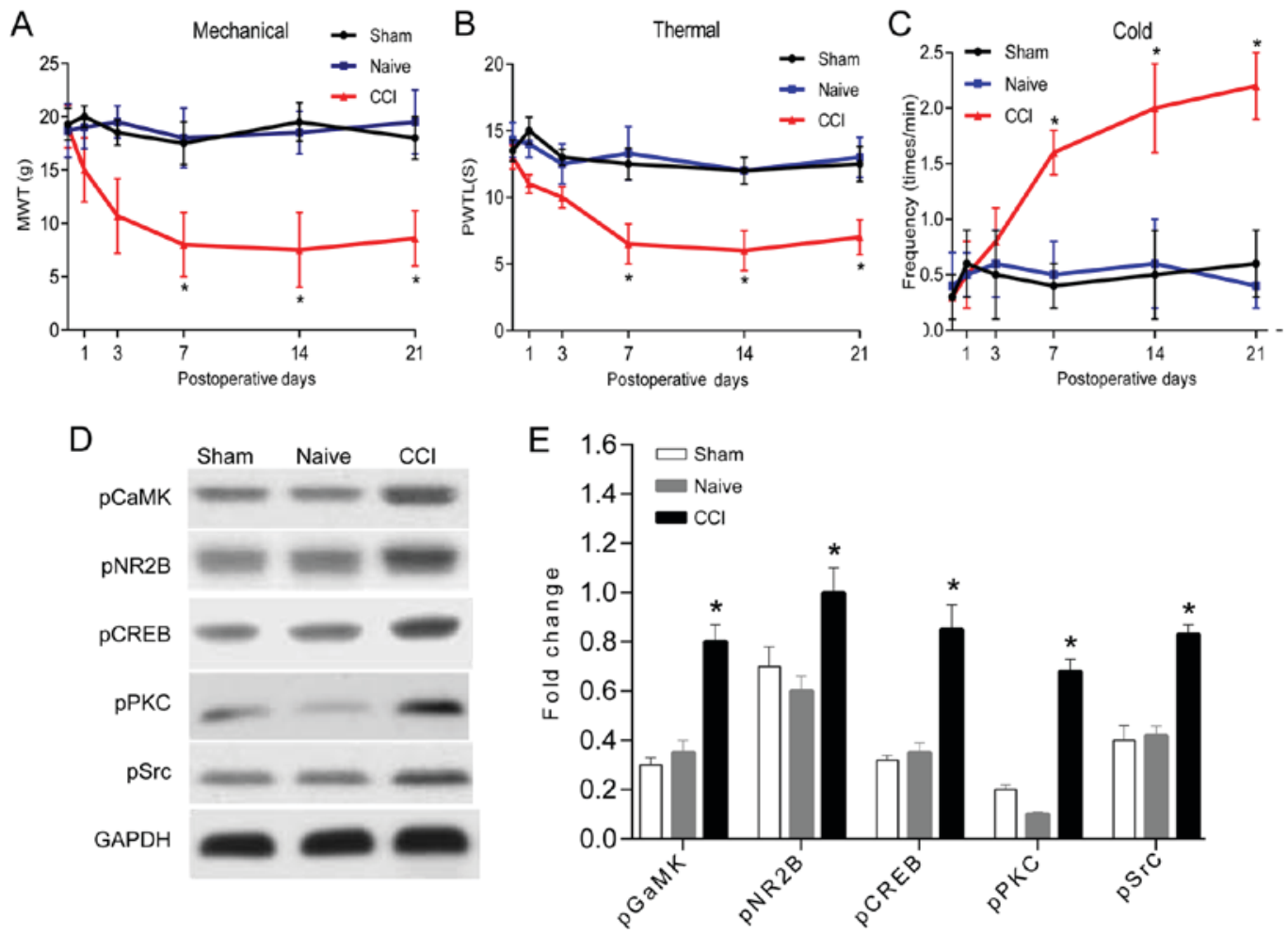

Figure 1. Changes of behavior and neuronal synaptic plasticity in rats after CCI. (A-C) Changes of mechanical threshold, thermal stimulation threshold and cold stimulation threshold in a time-dependent manner $(n=8)$. ( $D$ and $E$ ) The effect of Wnt-3a inhibitor on synaptic plasticity was detected by western blotting $(\mathrm{n}=3)(\mathrm{P}<0.05)$. CCI, chronic constriction injury.

\section{Results}

Changes of behavior and neuronal synaptic plasticity in rats after $C C I$. There were no statistically significant differences in the threshold values of mechanical pain threshold, thermal stimulus injury threshold and cold stimulus injury threshold between the hind feet of each rat before and after operation (Fig. 1). Therefore, the average value of left and right foot was taken for analysis. No significant difference was observed between the naive and sham groups $(\mathrm{P}>0.05)$. In the $\mathrm{CCI}$ group, hind paw mechanical pain threshold and thermal stimulus injury threshold of the CCI group started to decrease on the 7th day compared to the naive and sham groups $(\mathrm{P}<0.05)$, which reached the lowest value on the 14th day after operation (Fig. 1A and B). The positive reaction number of cold stimulation threshold in the CCI group was significantly higher than that in the naive and sham groups since the 7th day after operation ( $\mathrm{P}<0.05$; Fig. 1C).

In order to observe the effect of CCI on the synaptic plasticity of spinal dorsal horn neurons, the expression of synaptic plasticity-related molecules was detected by western blotting. The phosphorylation levels of synaptic plasticity of $\mathrm{Ca}^{2+} /$ calmodulin-dependent kinase II (CaMK II), glutamatergic receptor NR2B, CREB, PKC and tyrosine kinase Src were significantly altered on the 7th day after operation compared to the Sham group $(\mathrm{P}<0.05$; Fig. 1D), suggesting that CCI leads to the alteration of the neuronal plasticity of spinal dorsal horn, sensitization of the central nervous system, thus eventually resulting in the decrease of mechanical pain sensitivity threshold and cold pain sensitivity threshold in the CCI rats.
Wnt signaling pathway was activated in the CCI model. The transcription levels of Wnt-3a, Frizzled 4 and $\beta$-catenin at different time-points in the control, sham and CCI groups were detected by RT-PCR. The results demonstrated that compared with the control group, the expression of Wnt-3a, Frizzled 4 and $\beta$-catenin in the sham group are not significantly altered, while the expression of Wnt-3a in the CCI group was significantly increased on the 1st day after operation and remained at a high level for 21 days $(\mathrm{P}<0.05 ;$ Fig. $2 \mathrm{~A})$. Frizzled 4 was significantly higher in the CCI group during the 21-day observation period than that in the control and sham groups (Fig. 2B). The mRNA level of $\beta$-catenin was also markedly increased within 4 weeks after operation ( $\mathrm{P}<0.01$; Fig. $2 \mathrm{C})$.

Western blotting was performed to detect the protein levels of Wnt-3a, Frizzled 4 and $\beta$-catenin. Consistent with the mRNA and protein expression of Wnt-3a was significantly increased within 7 days after injury. Moreover, the protein levels of Frizzled 4 and $\beta$-catenin significantly increased from the first day after injury and remained at high levels after 14 days $(\mathrm{P}<0.05$; Fig. $2 \mathrm{D}$ and $\mathrm{E})$.

Intrathecal injection of IWP-2 relieved CCI-induced neuropathic pain and reduced neuronal synaptic plasticity. No statistically significant differences were shown in baseline values of the mechanical pain threshold, thermal stimulus injury threshold and cold stimulus injury threshold between the treatment and control groups at each time-point ( $\mathrm{P}>0.05$; Fig. $3 \mathrm{~A}$ and $\mathrm{C}$ ). The mechanical stimulation of rats in the treatment group exerted statistical significance on the 3rd day after operation compared with those in the control group (Fig. 3A), and thermal stimulation threshold and cold 

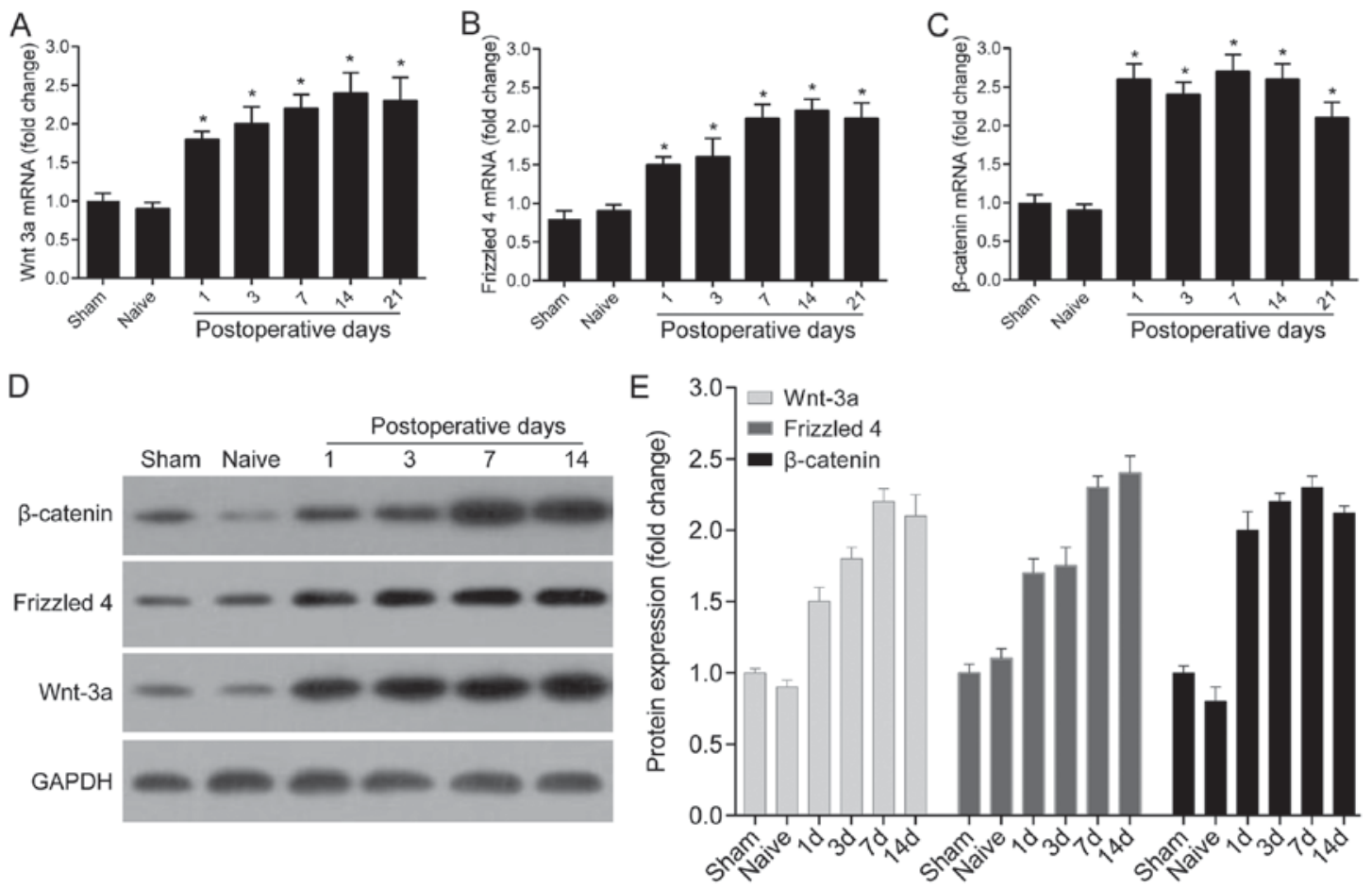

Figure 2. Wnt signaling pathway was activated in the CCI model. (A-C) The mRNA levels of Wnt-3a, Frizzled 4 and $\beta$-catenin in the spinal dorsal horn of Naive, Sham and treatment group were detected by RT-PCR (n=3). (D and E) Western blotting was performed to detect and quantify the expression of Wnt-3a, Frizzled 4 and $\beta$-catenin in Naive, Sham and treatment group $(\mathrm{n}=3)\left({ }^{*} \mathrm{P}<0.05\right)$. CCI, chronic constriction injury.
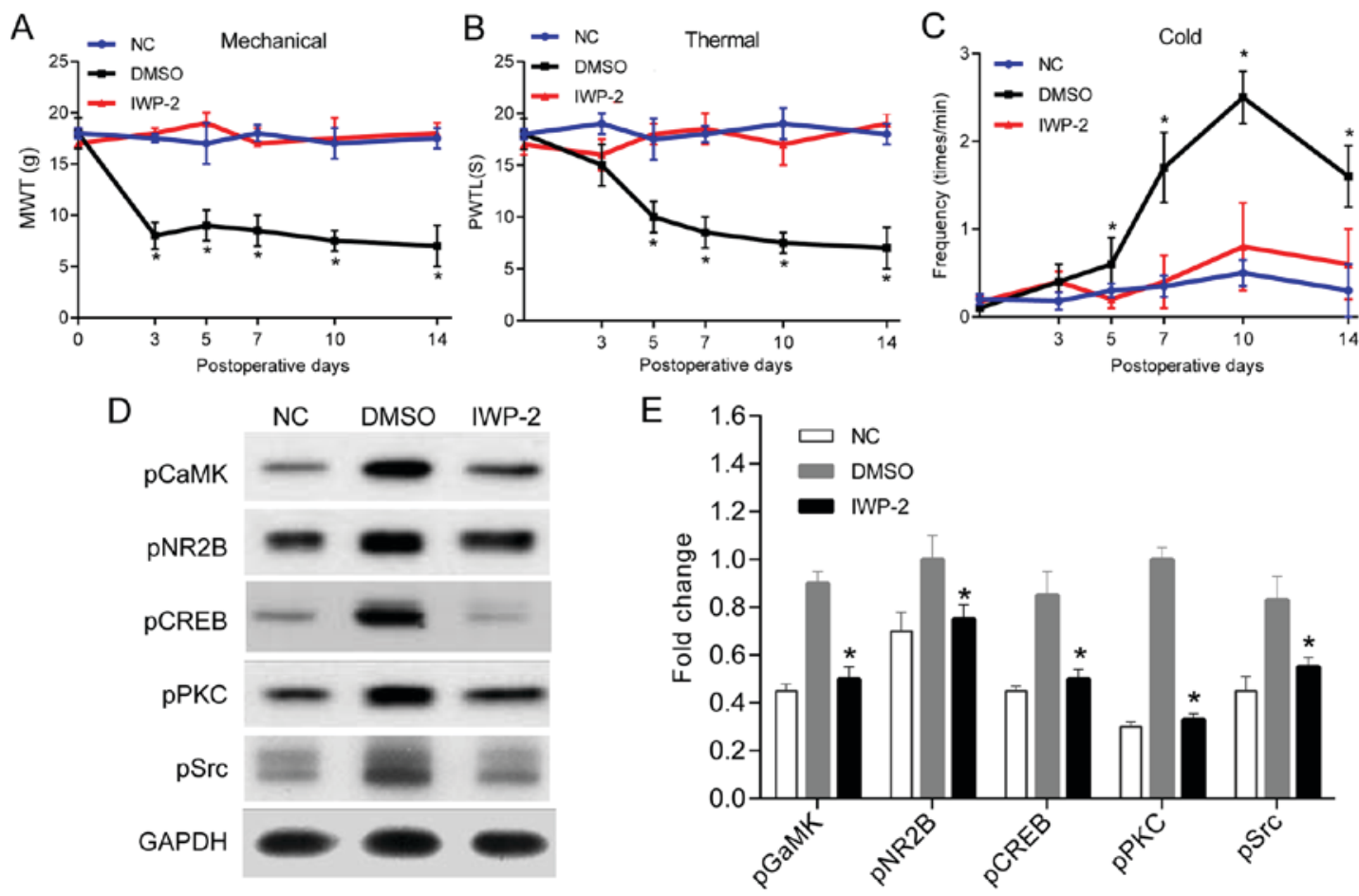

Figure 3. Intrathecal injection of IWP-2 relieved CCI-induced neuropathic pain and reduced neuronal synaptic plasticity. In total, 18 SD rats were randomly divided into treatment group, DMSO group and NC group. Bilateral sciatic nerve ligation was performed in the first two groups, and Wnt-3a inhibitor IWP-2 was intrathecally administered in treatment group. Rats in DMSO group were intrathecally injected with the isodose DMSO. Only intrathecal catheterization was performed in rats of NC group. Behavioral measurements were performed preoperatively, on the day of surgery, 3rd day and 5th day after IWP-2 treatment. (A-C) The changes of mechanical threshold, thermal stimulation threshold and cold stimulation threshold over time were observed (n=6). (D and E) The phosphorylation levels of CaMK II, NR2B, CREB, PKC and Src in each treatment group was detected by western blotting $(\mathrm{n}=3)\left({ }^{*} \mathrm{P}<0.05\right)$. CCI, chronic constriction injury.

stimulation threshold exhibited notable difference on the 5th day $(\mathrm{P}<0.05$; Fig. 3B and $\mathrm{C})$.
There were no significant differences in the phosphorylation levels of CaMK II, NR2B, CREB, PKC and Src between 


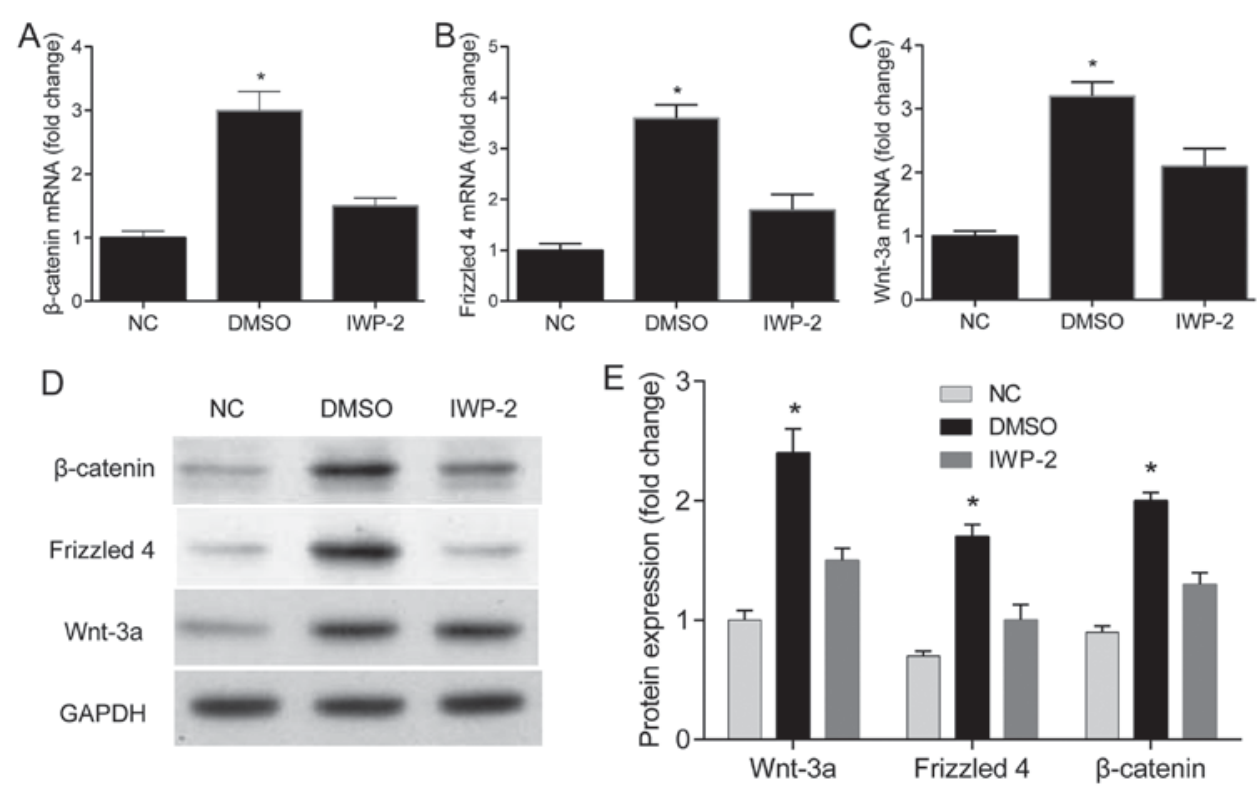

Figure 4. Intrathecal injection of IWP-2 inhibits the expression of Wnt-3a, Frizzled 4 and $\beta$-catenin. (A-C) The effects of IWP-2 on the mRNA levels of Wnt-3a, Frizzled 4 and $\beta$-catenin $(n=3)\left({ }^{*} P<0.05\right)$. ( $D$ and $\left.E\right)$ The effects of IWP-2 on the protein levels of Wnt-3a, Frizzled 4 and $\beta$-catenin $(n=3)(" P<0.05)$.

the treatment and control groups. However, the expression of CaMK II, NR2B, CREB, PKC and Src in the treatment group were significantly different on the 7th day after administration compared with those in the control group (Fig. 3D and E).

Intrathecal injection of IWP-2 inhibits the expression of Wnt-3a, Frizzled 4 and $\beta$-catenin. Compared with the rats injected with DMSO, the mRNA and protein levels of Wnt-3a, Frizzled 4 and $\beta$-catenin of rats in the treatment group were significantly increased after 7 days of administration $(\mathrm{P}<0.05)$. However, no changes of the mRNA and protein levels of Wnt-3a, Frizzled 4 and $\beta$-catenin were observed between the treatment and control groups (Fig. 4).

\section{Discussion}

NP is caused by nervous system injury or inflammation, accompanied by dysfunction and pain signal generation and conduction disorder. The main symptom of NP is hyperalgesia and spontaneous pain NP, which is independent of the persistence of tissue damage and noxious stimuli and considered as a nervous system disease (29-31). In recent years, studies have found that the nociceptive sensitization of the peripheral and spinal cord in the pathological state of neuropathic pain is characterized by abnormal neuronal discharge, abnormal activation of the sympathetic nervous system, dysfunction of the central down descending system, the activity modification of the ion channel and the activation of microglia.

Wnt is a secreted protein related to development of various biological processes, including proliferation, cell trafficking, polarization, and cell migration $(32,33)$. The Wnt protein specifically binds to the N-terminal cysteine-rich region of the Frizzled $(\mathrm{Fz})$ receptor and functions through the classical $\mathrm{Wnt} / \beta$-catenin pathway as well as non-classical Wnt/PCP or $\mathrm{Wnt} / \mathrm{Ca}$ pathway $(2,34,35)$. Studies have shown that $\mathrm{Wnt}$ signaling abnormalities might be related to axonal injury after aplastic failure and the occurrence of certain mental diseases (36-38). In a chronic pain model induced by multiple sclerosis, Wnt expression was upregulated in the spinal dorsal horn, which caused disease progression (39). Zhang et al (40) found that aberrant activation of Wnt signaling pathway is correlated with the pathological process of NP in rodents. Wnt signaling pathway played a role in NP by activating the proinflammatory cytokines IL-18 and TNF- $\alpha$, as well as glutamatergic receptor NR2B and its downstream $\mathrm{Ca}^{2+}$ signaling pathway.

So far, the CCI and spinal nerve ligation (SNL) models are still the two most commonly used animal models for the study of neuropathic chronic pain. The CCI model cleverly combines neuropathic and inflammatory pain. Precisely, ectopic discharges caused by axonal injury promotes the immune cells to release inflammatory mediators, which leads to the pain induced by peripheral and central sensitization. Our study found that CCI alters the behavioral parameters of neuropathic pain in rats. At the same time, the phosphorylation level of glutamate receptor (NMDR) subtype NR2B, a synaptic plasticity-related protein, was significantly increased, as well as the phosphorylation level of tyrosine kinase Src, which increased the receptor current. All of these indicated that CCI alters synaptic plasticity by regulating the phosphorylation and current of synaptic receptors, while increased synaptic plasticity results in central sensitization and reduced pain threshold. The expression of Wnt signaling molecules were also significantly increased after CCI treatment in our study, suggesting that the Wnt signaling pathway might be involved in CCI-induced neuropathic pain in rats.

Application of IWP-2, the Wnt-3a inhibitor, significantly increased PWMT in SD rats treated with IWP-2 compared to those in the control group, indicating that IWP-2 might become a new type of analgesic. We proposed the possible mechanism underlying the pain regulated by the Wnt signaling pathway. That was, the activation of Wnt signal molecules is involved in the production of neuropathic pain. Wnt-3a phosphorylated the $\beta$-catenin via the combination with Frizzled 4, a postsynaptic 
membrane-specific receptor, which resulted in the accumulation of $\beta$-catenin to the nucleus and then initiated the transcription of downstream target genes. The activation of target genes led to increased expression of glutamate receptors and the increased activity of their corresponding phosphorylase, resulting in synaptic plasticity. Increased synaptic plasticity resulted in central sensitization and reduced pain threshold.

In conclusion, our data showed that intrathecal injection of IWP-2 improved neuropathic pain by inhibiting the Wnt/ $\beta$-catenin pathway in CCI rats, which may provide a new target for the treatment of neuropathic pain.

\section{Acknowledgements}

Not applicable.

\section{Funding}

No funding was received.

\section{Availability of data and materials}

All data generated or analyzed during this study are included in this published article.

\section{Authors' contributions}

YZ and ZY designed the study, performed the experiments, established the animal models, collected and analyzed the data. YZ prepared the manuscript. Both authors have read and approved the final study.

\section{Ethics approval and consent to participate}

This study was approved by the Animal Ethics Committee of Jining No. 1 People's Hospital Animal Center (Jining, China).

\section{Patient consent for publication}

Not applicable.

\section{Competing interests}

The authors declare that they have no competing interests.

\section{References}

1. Haanpää M, Attal N, Backonja M, Baron R, Bennett $M$, Bouhassira D, Cruccu G, Hansson P, Haythornthwaite JA, Iannetti GD, et al: NeuPSIG guidelines on neuropathic pain assessment. Pain 152: 14-27, 2011.

2. Jensen TS, Baron R, Haanpää M, Kalso E, Loeser JD, Rice AS and Treede RD: A new definition of neuropathic pain. Pain 152 2204-2205, 2011.

3. Cruccu G and Truini A: A review of neuropathic pain: From guidelines to clinical practice. Pain Ther 6 (Suppl 1): 35-42, 2017.

4. Amato F, Duse G, Consoletti L, Lo Presti C, Firetto V, Ciliberto G, Parigi LA, Palmieri V and Mazza M: Efficacy and safety of 5\% lidocaine-medicated plasters in localized pain with neuropathic and/or inflammatory characteristics: An observational, realworld study. Eur Rev Med Pharmacol Sci 21: 4228-4235, 2017.

5. O'Connor $\mathrm{AB}$ and Dworkin $\mathrm{RH}$ : Treatment of neuropathic pain: An overview of recent guidelines. Am J Med 122 (Suppl): S22-S32, 2009.
6. Horváth G, Gölöncsér F, Csölle C, Király K, Andó RD, Baranyi M, Koványi B, Máté Z, Hoffmann K, Algaier I, et al: Central P2Y12 receptor blockade alleviates inflammatory and neuropathic pain and cytokine production in rodents. Neurobiol Dis 70: 162-178, 2014.

7. Ishikawa T, Miyagi M, Kamoda H, Orita S, Eguchi Y, Arai G, Suzuki M, Sakuma Y, Oikawa Y, Inoue G, et al: Differences between tumor necrosis factor- $\alpha$ receptors types 1 and 2 in the modulation of spinal glial cell activation and mechanical allodynia in a rat sciatic nerve injury model. Spine 38: 11-16, 2013.

8. Lefèvre Y, Amadio A, Vincent P, Descheemaeker A, Oliet SH, Dallel R and Voisin DL: Neuropathic pain depends upon D-serine co-activation of spinal NMDA receptors in rats. Neurosci Lett 603: 42-47, 2015.

9. Tiwari V, Guan Y and Raja SN: Modulating the delicate glial-neuronal interactions in neuropathic pain: Promises and potential caveats. Neurosci Biobehav Rev 45: 19-27, 2014.

10. Bolay $\mathrm{H}$ and Moskowitz MA: Mechanisms of pain modulation in chronic syndromes. Neurology 59 (Suppl 2): S2-S7, 2002.

11. Kawasaki Y, Zhang L, Cheng JK and Ji RR: Cytokine mechanisms of central sensitization: Distinct and overlapping role of interleukin-1beta, interleukin-6, and tumor necrosis factor-alpha in regulating synaptic and neuronal activity in the superficial spinal cord. J Neurosci 28: 5189-5194, 2008.

12. Finnerup NB, Attal N, Haroutounian S, McNicol E, Baron R, Dworkin RH, Gilron I, Haanpää M, Hansson P, Jensen TS, et al: Pharmacotherapy for neuropathic pain in adults: A systematic review and meta-analysis. Lancet Neurol 14: 162-173, 2015.

13. Jia HB, Jin Y, Ji Q, Hu YF, Zhou ZQ, Xu JG and Yang JJ: Effects of recombinant human erythropoietin on neuropathic pain and cerebral expressions of cytokines and nuclear factor-kappa B. Can J Anaesth 56: 597-603, 2009.

14. Zhang L, Fu ZJ, Sun T, Zhao XL, Song WG, Jia MR and Wei GF: Expression of NF-kappaB and TNF-alpha in spinal dorsal horn in a rat model of neuropathic pain. Zhonghua Yi Xue Za Zhi 90: 1067-1071, 2010 (In Chinese).

15. Song XJ, Wang ZB, Gan Q and Walters ET: cAMP and cGMP contribute to sensory neuron hyperexcitability and hyperalgesia in rats with dorsal root ganglia compression. J Neurophysiol 95: 479-492, 2006.

16. Cenac N, Altier C, Chapman K, Liedtke W, Zamponi G and Vergnolle N: Transient receptor potential vanilloid-4 has a major role in visceral hypersensitivity symptoms. Gastroenterology 135: 937-946, 2008.

17. Cenac N, Altier C, Motta JP, d'Aldebert E, Galeano S, Zamponi GW and Vergnolle N: Potentiation of TRPV4 signalling by histamine and serotonin: An important mechanism for visceral hypersensitivity. Gut 59: 481-488, 2010.

18. Facer P, Casula MA, Smith GD, Benham CD, Chessell IP, Bountra C, Sinisi M, Birch R and Anand P: Differential expression of the capsaicin receptor TRPV1 and related novel receptors TRPV3, TRPV4 and TRPM8 in normal human tissues and changes in traumatic and diabetic neuropathy. BMC Neurol 7: 11, 2007.

19. Tung KW, Behera D and Biswal S: Neuropathic pain mechanisms and imaging. Semin Musculoskelet Radiol 19: 103-111, 2015.

20. Cervantes-Durán C, Vidal-Cantú GC, Godínez-Chaparro B and Granados-Soto V: Role of spinal 5-HT2 receptors subtypes in formalin-induced long-lasting hypersensitivity. Pharmacol Rep 68: 434-442, 2016.

21. Madishetti S, Schneble N, König C, Hirsch E, Schulz S, Müller JP and Wetzker R: PI3K $\gamma$ integrates cAMP and Akt signalling of the $\mu$-opioid receptor. Br J Pharmacol 171: 3328-3337, 2014.

22. Manet R, Fabre N, Moyse E, Laurent B and Schmidt EA: Intracranial hypertension is painless! Acta Neurochir Suppl (Wien) 122: 275-277, 2016.

23. Wu J, Xu Y, Pu S, Jiang W and Du D: p38/MAPK inhibitor modulates the expression of dorsal horn $\mathrm{GABA}(\mathrm{B})$ receptors in the spinal nerve ligation model of neuropathic pain. Neuroimmunomodulation 18: 150-155, 2011.

24. Zhang X, Zheng H, Zhu HY, Hu S, Wang S, Jiang X and Xu GY: Acute effects of transforming growth factor-betal on neuronal excitability and involvement in the pain of rats with chronic pancreatitis. J Neurogastroenterol Motil 22: 333-343, 2016.

25. Komiya $\mathrm{Y}$ and Habas R: Wnt signal transduction pathways. Organogenesis 4: 68-75, 2008.

26. Davis EK, Zou Y and Ghosh A: Wnts acting through canonical and noncanonical signaling pathways exert opposite effects on hippocampal synapse formation. Neural Dev 3: 32, 2008. 
27. Chen J, Park CS and Tang SJ: Activity-dependent synaptic Wnt release regulates hippocampal long term potentiation. J Biol Chem 281: 11910-11916, 2006

28. Logan CY and Nusse R: The Wnt signaling pathway in development and disease. Annu Rev Cell Dev Biol 20: 781-810, 2004

29. Datta S, Chatterjee K, Kline RH IV and Wiley RG: Behavioral and anatomical characterization of the bilateral sciatic nerve chronic constriction (bCCI) injury: Correlation of anatomic changes and responses to cold stimuli. Mol Pain 6: 7, 2010.

30. Hargreaves K, Dubner R, Brown F, Flores C and Joris J: A new and sensitive method for measuring thermal nociception in cutaneous hyperalgesia. Pain 32: 77-88, 1988.

31. Gangadhar M, Mishra RK, Sriram D and Yogeeswari P: Future directions in the treatment of neuropathic pain: A review on various therapeutic targets. CNS Neurol Disord Drug Targets 13 : 63-81, 2014.

32. Mohammed MK, Shao C, Wang J, Wei Q, Wang X, Collier Z, Tang S, Liu H, Zhang F, Huang J, et al: Wnt/ $\beta$-catenin signaling plays an ever-expanding role in stem cell self-renewal, tumorigenesis and cancer chemoresistance. Genes Dis 3: 11-40, 2016.

33. Moon RT, Kohn AD, De Ferrari GV and Kaykas A: WNT and beta-catenin signalling: Diseases and therapies. Nat Rev Genet 5 : 691-701, 2004

34. Hering $H$ and Sheng M: Direct interaction of Frizzled-1, -2, -4, and -7 with PDZ domains of PSD-95. FEBS Lett 521: 185-189, 2002.
35. Verkaar F and Zaman GJ: New avenues to target Wnt/ $\beta$-catenin signaling. Drug Discov Today 16: 35-41, 2011.

36. Cerpa W, Toledo EM, Varela-Nallar L and Inestrosa NC: The role of Wnt signaling in neuroprotection. Drug News Perspect 22: 579-591, 2009.

37. Liu Y, Wang X, Lu CC, Kerman R, Steward O, Xu XM and Zou Y: Repulsive Wnt signaling inhibits axon regeneration after CNS injury. J Neurosci 28: 8376-8382, 2008.

38. Suh HI, Min J, Choi KH, Kim SW, Kim KS and Jeon SR: Axonal regeneration effects of Wnt3a-secreting fibroblast transplantation in spinal cord-injured rats. Acta Neurochir (Wien) 153 1003-1010, 2011.

39. Yuan S, Shi Y and Tang SJ: Wnt signaling in the pathogenesis of multiple sclerosis-associated chronic pain. J Neuroimmune Pharmacol 7: 904-913, 2012.

40. Zhang YK, Huang ZJ, Liu S, Liu YP, Song AA and Song XJ: WNT signaling underlies the pathogenesis of neuropathic pain in rodents. J Clin Invest 123: 2268-2286, 2013.

(i) $\ominus$ This work is licensed under a Creative Commons Attribution-NonCommercial-NoDerivatives 4.0 International (CC BY-NC-ND 4.0) License. 